\title{
Exposure Treatment Vehicle Amount
}

National Cancer Institute

\section{Source}

National Cancer Institute. Exposure Treatment Vehicle Amount. NCI Thesaurus. Code C87883.

The quantity of exposure to an excipient in a treatment. 